Article

\title{
Engineering Porous Poly(lactic acid) Scaffolds with High Mechanical Performance via a Solid State Extrusion/Porogen Leaching Approach
}

\author{
Hua-Mo Yin, Jing Qian, Jin Zhang, Zai-Fu Lin, Jian-Shu Li, Jia-Zhuang Xu * and Zhong-Ming Li * \\ College of Polymer Science and Engineering, State Key Laboratory of Polymer Materials Engineering, \\ Sichuan University, Chengdu 610065, China; scugfzyhm@163.com (H.-M.Y.); JingQ_scu@163.com (J.Q.); \\ zhangjin500782@126.com (J.Z.); Linzfscu@163.com (Z.-F.L.); jianshu_li@scu.edu.cn (J.-S.L.) \\ * Correspondence: jzxu@scu.edu.cn (J.-Z.X.); zmli@scu.edu.cn (Z.-M.L.); Tel.: +86-28-8540-5402 (Z.-M.L.); \\ Fax:+86-28-8540-0211 (Z.-M.L.)
}

Academic Editor: Jianxun Ding

Received: 3 March 2016; Accepted: 26 May 2016; Published: 31 May 2016

\begin{abstract}
A knotty issue concerning the poor mechanical properties exists in the porogen leaching approach to porous scaffolds, despite its advantage in tuning pore structure. To address this hurdle, solid state extrusion (SSE) combined with porogen leaching was utilized to engineer porous scaffolds of poly(lactic acid) (PLA). Advances introduced by poly(ethylene glycol) (PEG) caused the PLA ductile to be processed and, on the other hand, enabled the formation of interconnected pores. Thus, a well-interconnected porous architecture with high connectivity exceeding $97 \%$ and elevated porosity over $60 \%$ was obtained in the as-prepared PLA scaffolds with the composition of $\mathrm{NaCl}$ higher than $75.00 \mathrm{wt} \%$ and PEG beyond $1.25 \mathrm{wt} \%$. More strikingly, the pore walls of macropores encompassed countless micropores and rough surface topography, in favor of transporting nutrients and metabolites as well as cell attachment. The prominent compressive modulus of the PLA scaffolds was in the range of 85.7-207.4 MPa, matching the normal modulus of human trabecular bone (50-250 MPa). By means of alkaline modification to improve hydrophilicity, biocompatible porous PLA scaffolds exhibited good cell attachment. These results suggest that the SSE/porogen leaching approach provides an eligible clue for fabricating porous scaffolds with high mechanical performance for use as artificial extracellular matrices.
\end{abstract}

Keywords: solid state extrusion; poly(lactic acid); scaffolds; mechanical reinforcement; porosity

\section{Introduction}

A foremost strategy to substitute autografts is the utilization of three-dimensional porous scaffold, which serves as a temporary template for cell adhesion, proliferation, along with differentiation to form a functional tissue [1,2] and effectively overcomes the problems of lacking availability and allografts suffering from existent complications. Of particular importance is the fabrication method, since it endows scaffolds with the required physical and biological properties for tissue regeneration [3-6]. A wide spectrum of techniques have been proposed to engineer porous scaffolds, including fiber bonding [7], porogen leaching [8-14], emulsion freeze drying [15], gas foaming [16,17], thermally induced phase separation [18], electrospinning [19,20], and rapid prototyping [21]. Among them, porogen leaching is perceived as the most expedient and economic access to porous structures. The tunable pore shape, size, and porosity are easily acquired through control over particle parameters such as appearance, dimension, and fraction. However, despite its distinct convenience, potential toxicity from residual organic solvents poses an intrinsic limitation to bone repair [22].

To pursue a hazarding solvent-free route, a combination of melt processing with innoxious porogen leaching seems to be straightforward, convenient, and efficient. Compression molding in 
conjunction with water-soluble salt removal has become a versatile way to devise tissue engineering scaffolds. The obtained scaffolds are constitutive of uniformly interconnected and independently controllable pore networks [10]. This strategy applies equally well to extrusion and injection molding [23,24]. Unfortunately, in spite of the feasibility, porous scaffolds prepared by these approaches always suffer from poor mechanical properties, which can hardly fulfill the requirements of the host bone tissue engineering [25]. Here, it is emphasized that the scarcity in mechanical properties of artificial scaffolds is also a common and intractable issue faced by other fabrication techniques. Even worse, potential thermal degradation derived from a high processing temperature further deteriorates the mechanical properties. Therefore, ameliorating the mechanical performance of bone regeneration scaffolds remains challenging.

Strong interest in constructing high strength and modulus polymer products results in the emergence of solid state extrusion (SSE), which garners superior self-reinforced materials without thermal degradation [26-30]. The principle of SSE is to compulsively extrude polymeric billets through convergent dies just below the melting point. During SSE, shear deformation induces the formation of well-defined fibrillar structures in the extruded materials, consequently leading to a remarkable increase in mechanical properties. One representative study registered that flexural strength and modulus increased 1.7-fold and 3.0-fold for SSE poly(lactic acid) (PLA) compared to the melt-extruded counterpart, respectively [31].

The facile yet versatile SSE approach exhibits technical advances in comparison to other methods, such as avoiding organic solvents, repelling molecular weight degradation, and improving mechanical properties. In this contribution, we attempted to fabricate PLA porous scaffolds by combining SSE and hydrosoluble sodium chloride ( $\mathrm{NaCl}$ ) leaching. PLA, a biodegradable, biocompatible, and absorbable polyester, is recognized as one of the most attractive scaffold materials [32] for being successfully implanted in vivo, such as in human heart-blood vessels [33,34]. Nevertheless, innate poor toughness of PLA is destructive to processability, which is an obstacle to the wider use in the fields of tissue engineering [35]. With an accent on optimizing workability of PLA, biocompatible poly(ethylene glycol) (PEG) was introduced as an effective plasticizer for PLA [36-40]. Meanwhile, water-soluble PEG could serve as polymeric porogen and was expected to cooperate with $\mathrm{NaCl}$ to promote the generation of porous structures. Our results demonstrated that the SSE/porogen leaching technique is a feasible strategy to fabricate porous PLA scaffolds with a high compressive modulus, an interconnected interior structure, as well as a good cell adhesion capacity for tissue engineering.

\section{Materials and Methods}

\subsection{Materials}

PLA with L-lactide content of $99.8 \%$ was supplied by Zhejiang Hisun Biomaterials Co., Ltd. (Taizhou, China). The $M_{\mathrm{n}}$ and $M_{\mathrm{w}}$ were $9.0 \times 10^{4}$ and $19.5 \times 10^{4} \mathrm{~g} \cdot \mathrm{mol}^{-1}$, respectively. PEG (trade name Carbowax) with $M_{\mathrm{w}}=3350 \mathrm{~g} \cdot \mathrm{mol}^{-1}$ was purchased from Dow Chemical Company (Midland, MI, USA). $\mathrm{NaCl}$ as particulate porogen was purchased from Chengdu Kelong Chemical Reagent Factory (Chengdu, China). The particle size was in the range of 25-74 $\mu \mathrm{m}$. All chemicals for cell experiment were provided by the Chengdu Baoke Biotechnology Co., Ltd. (Chengdu, China).

\subsection{Preparation of PLA/PEG/NaCl Mixtures}

Ternary blends of PLA/PEG/NaCl were melt-compounded using a torque rheometer (XSS-300, Shanghai Kechuang Rubber Plastic Mechanical Equipment Co., Ltd., Shanghai, China). PLA, PEG, and $\mathrm{NaCl}$ with the formulae as listed in Table 1 were dried at $45^{\circ} \mathrm{C}$ for $48 \mathrm{~h}$ in vacuum prior to blending. The mixing process was conducted at $190{ }^{\circ} \mathrm{C}$ with a rotation speed of $30 \mathrm{rpm}$ for $7 \mathrm{~min}$. Subsequently, the blends were shattered into small granules via a universal high-speed smashing machine (Beijing Kewei Yongxing Instrument Co., Ltd., Beijing, China). Binary blends of PLA/ $\mathrm{NaCl}$ could not be prepared due to inferior processability. Herein, the code $\mathrm{P}_{75-20}$ denotes the sample composed by 
$75.00 \mathrm{wt} \% \mathrm{NaCl}, 5.00 \mathrm{wt} \%$ PEG, and $20.00 \mathrm{wt} \%$ PLA, where the relative mass faction (MR) of PEG in the polymeric components is $20 \mathrm{wt} \%$. For brevity, the rest is deduced by analogy.

Table 1. Composition formulation and theoretical porosity of ternary blends of poly(lactic acid) (PLA)/poly(ethylene glycol) (PEG)/NaCl.

\begin{tabular}{|c|c|c|c|c|c|}
\hline & $\mathbf{P}_{75-5}$ & $\mathbf{P}_{75-10}$ & $\mathbf{P}_{75-20}$ & $\mathbf{P}_{80-20}$ & $\mathbf{P}_{85-20}$ \\
\hline $\mathrm{NaCl}(w \mathrm{t} \%)$ & 75.00 & 75.00 & 75.00 & 80.00 & 85.00 \\
\hline PEG (wt \%) & 1.25 & 2.50 & 5.00 & 4.00 & 3.00 \\
\hline PLA (wt \%) & 23.75 & 22.50 & 20.00 & 16.00 & 12.00 \\
\hline $\operatorname{MR}(w t \%){ }^{1}$ & 5 & 10 & 20 & 20 & 20 \\
\hline Theoretical porosity (\%) & 65.66 & 67.55 & 71.29 & 76.28 & 81.62 \\
\hline
\end{tabular}

${ }^{1} \mathrm{MR} w \mathrm{t} \%=m_{\mathrm{PEG}} /\left(m_{\mathrm{PEG}}+m_{\mathrm{PLA}}\right)$.

\subsection{Preparation of Porous PLA Scaffolds}

A home-made SSE apparatus was employed to prepare porous PLA scaffolds. Diameters of cylindrical channel in the barrel and the conical die were 20 and $10 \mathrm{~mm}$, respectively, corresponding to the extrusion draw ratio of 4 . A cylindrical billet of the PLA/PEG/ $\mathrm{NaCl}$ mixture was first annealed at $185^{\circ} \mathrm{C}$ for $15 \mathrm{~min}$ by compression molding and slowly cooled to $55^{\circ} \mathrm{C}$ at a rate of $3{ }^{\circ} \mathrm{C} \cdot \mathrm{min}^{-1}$. Then, the billet was heated to $155^{\circ} \mathrm{C}$ and kept for $10 \mathrm{~min}$ to reach a thermal balance, and was then extruded through the die. Meanwhile, the drawing rate was maintained slowly enough to guarantee ample time for the deformation of the billet and to gain an impeccable cylindrical extrudate. Following the machining of entitative specimens, cylinders and discs were immersed in distilled water at $37^{\circ} \mathrm{C}$ for a continued $36 \mathrm{~h}$ to leach out the $\mathrm{NaCl}$ and PEG. Finally, the prepared PLA scaffolds were dried at $37^{\circ} \mathrm{C}$ in a vacuum to a constant weight. Figure 1 illustrates the preparation process of porous PLA scaffolds as previously described.

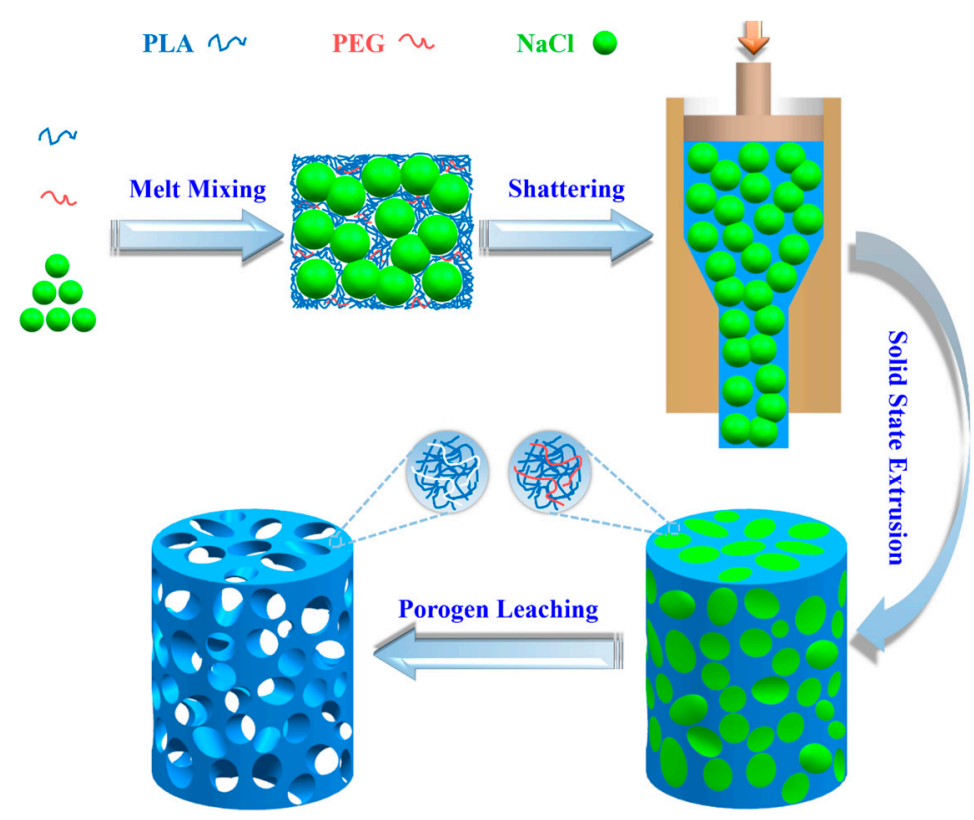

Figure 1. Schematic of fabricating porous PLA scaffolds. The size of $\mathrm{NaCl}$ ranges from 25 to $74 \mu \mathrm{m}$, and the diameter of as-prepared porous scaffolds is $10 \mathrm{~mm}$.

\subsection{Residual Mass, Connectivity, and Porosity Measurement}

Residual weight percentage of $\mathrm{NaCl}$ in the PLA scaffolds was determined by thermogravimetric analysis (Q600, TA Instruments Inc., New Castle, DE, USA). The sample was heated at a constant rate of $20^{\circ} \mathrm{C} \cdot \mathrm{min}^{-1}$ from 30 to $600{ }^{\circ} \mathrm{C}$. In order to confirm that the residual weight at $600{ }^{\circ} \mathrm{C}$ solely resulted 
from $\mathrm{NaCl}$, the weight loss curve of pure PEG was present as a control. The connectivity of porous PLA scaffolds was calculated by the following equation:

$$
\text { Connectivity }=\left(1-\frac{\omega_{\text {residual }}}{\omega_{\text {original }}}\right) \times 100 \%,
$$

where $\omega_{\text {residual }}$ and $\omega_{\text {original }}$ are the residual and original weight fraction of $\mathrm{NaCl}$, respectively.

Porosity of PLA scaffolds was measured by a gravimetric method according to the following equation:

$$
\text { Porosity }=\left(1-\frac{\rho}{\rho_{\mathrm{c}}}\right) \times 100 \% \text {, }
$$

where apparent density $(\rho)$ of PLA scaffolds is defined as the mass divided by the volume of porous PLA scaffolds, while $\rho_{\mathrm{c}}$ represents the density of compact PLA $\left(1.27 \mathrm{~g} \cdot \mathrm{cm}^{-3}\right)$. Here, the theoretical values of porosity by assuming the complete extraction of PEG and $\mathrm{NaCl}$ are tabulated in Table 1.

\subsection{Scanning Electron Microscopy (SEM)}

Morphology observation was examined by a field-emission SEM (Inspect F50, FEI, Hillsboro, OR, USA) at an acceleration voltage of $20 \mathrm{kV}$. The observed specimens were fractured after freezing in liquid nitrogen for $\sim 30 \mathrm{~min}$ and then sputtered a thin golden layer. Pore size was quantified by measuring 200 randomly distributed pores for 3 times with image analysis software of Nano Measurer 1.2.0 (provided by Laboratory of Surface Chemistry and Catalysis, Department of Chemistry, Fudan University, Shanghai, China).

\subsection{Differential Scanning Calorimetry (DSC)}

Melting behavior was determined by a DSC instrument (Q2000, TA Instruments, New Castle, DE, USA). The samples (5-6 mg) were heated from 40 to $190{ }^{\circ} \mathrm{C}$ at a constant rate of $10{ }^{\circ} \mathrm{C} \cdot \mathrm{min}^{-1}$ under a nitrogen flow rate of $50 \mathrm{~mL} \cdot \mathrm{min}^{-1}$. The crystallinity $\left(X_{\mathrm{c}}\right)$ was calculated by $X_{\mathrm{c}}=\left[\left(\Delta H_{\mathrm{m}}-\Delta H_{\mathrm{cc}}\right) / \Delta H_{0}\right] \times 100 \%$, where $\Delta H_{\mathrm{m}}$ and $\Delta H_{\mathrm{cc}}$ delegate melting enthalpy and cold crystalline enthalpy, respectively. $\Delta H_{0}$ is the melting enthalpy of $100 \%$ crystalline PLA, $93.7 \mathrm{~J} \cdot \mathrm{g}^{-1}$ [41].

\subsection{Mechanical Properties}

Compressive property was carried out at ambient temperature using a universal mechanical testing machine (Model 5567, Instron Instruments, Norwood, MA, USA) at a crosshead speed of $1 \mathrm{~mm} \cdot \mathrm{min}^{-1}$ and with a $1-\mathrm{kN}$ load cell. Cylindrical samples with a diameter of $10 \mathrm{~mm}$ and a height of 9-10 mm were used for the measurement. An average value of 5 specimens in each group was presented with standard deviation.

\subsection{Water Contact Angle Analysis}

Wettability was qualitatively examined via the measuring water contact angle (WCA) using a contact angle goniometer (DA 30, Krüss, Hamburg, Germany) equipped with internal image analysis software. Distilled water $(2 \mu \mathrm{L})$ was dropped on the surface of dry PLA scaffolds at room temperature and the wetting process was recorded using a high-speed digital camera. Average WCA was obtained by performing on five random regions in a specimen.

\subsection{Cytotoxicity Test}

In vitro cell cytotoxicity experiment was performed using an extract solution method to assess material cytotoxicity. Rat bone marrow stromal cells (BMSCs) were seeded on a 96-well plate (3000 cells. well ${ }^{-1}$ ) and incubated in Dulbecco's modified eagle medium (DMEM) containing $10 \%$ fetal bovine serum and penicillin-streptomycin $\left(100 \mu \mathrm{g} \cdot \mathrm{mL}^{-1}\right)$ at $37{ }^{\circ} \mathrm{C}$ in a humidified $5 \%$ $\mathrm{CO}_{2}$ atmosphere for $24 \mathrm{~h}$. Then, the medium was completely removed and extract solution 
$(100 \mu \mathrm{L})$ was added to each well. After $24 \mathrm{~h}$ of incubation, the cell viability was analyzed by the 3-(4,5-dimethylthiazol-2-yl)-2,5-diphenyltetrazolium bromide (MTT) colorimetric assay. Specifically, $10 \mu \mathrm{L}$ of MTT solution ( $5 \mathrm{mg} \cdot \mathrm{mL}^{-1}$ in the final concentration) was added to each well and incubated for $5 \mathrm{~h}$. Afterwards, supernate was removed, and $100 \mu \mathrm{L}$ of dimethyl sulfoxide (DMSO) was put into each well to dissolve formazan crystals. The absorbance at $492 \mathrm{~nm}$ was measured by a microplate reader (KHB ST-360, Shanghai Kehua Bio-engineering Co., Ltd., Shanghai, China). The experiment of each specimen was performed six times.

\subsection{Cell Adhesion}

Cell attachment was used to examine the cytocompatibility of porous PLA scaffolds. Sterilized discs were seeded with BMSCs $\left(10,000\right.$ cells $^{-}$well $\left.^{-1}\right)$ in 48 -well plates and cultured in the above DMEM condition for $24 \mathrm{~h}$. For observing cell morphology, the samples were removed from the 48-well plates and rinsed three times with a phosphate-buffered saline (PBS). Then, $50 \mathrm{~mL}$ of the fluorescein diacetate (FDA; Sigma, St. Louis, MI, USA) was immediately added to each sample and incubated in darkness at $37^{\circ} \mathrm{C}$ for $15 \mathrm{~min}$. Subsequently, all samples were rinsed with PBS and observed by an inverted fluorescence microscopy (Eclipse TS100, Nikon, Tokyo, Japan). To quantitatively evaluate cell adhesion via CCK-8, discs after $24 \mathrm{~h}$ of incubation were transferred to other 48 -well plates. The DMEM media $(0.2 \mathrm{~mL})$ and CCK-8 solution $(20 \mu \mathrm{L})$ were added to each well, and transferred into a 96-well plate after $1 \mathrm{~h}$ of incubation. The microplate reader was utilized to measure the absorbance at $450 \mathrm{~nm}$.

\subsection{Statistical Analysis}

All data were expressed as mean \pm standard deviation. Statistical significance was examined by single-factor analysis of variance (ANOVA). A value of $p<0.05$ was considered statistically significant.

\section{Results and Discussion}

\subsection{Structural Integrity}

An integrated structure is a necessary prerequisite for PLA scaffolds to prevent premature collapse and to promote bone tissue regeneration in vivo. As evidenced by the existing literatures, inclusion of $\mathrm{NaCl}$ component depresses the chain mobility of PLA and results in inferior flowability [40]. Our preliminary exploration also found that there were visible cracks on the surface of PLA/NaCl extrudates; subsequently, the binary blends collapsed irreparably during the leaching process due to structural defect. In the melting extrusion of polymer/particulate blends, a tradeoff between flowability and porosity should be pursued, both of which are associated with particulate content. When particulate content was below $70.00 \mathrm{wt} \%$, the extrudates usually possessed low porosity and poor pore interconnectivity [42]. Further increases in particulate content cause a loss of flowability. As a concession, high temperature curing was used to assure the structure integrity and high porosity but at the expense of molecular weight and mechanical properties [23]. Pleasingly, in our study, even the as-prepared scaffold materials containing $\mathrm{NaCl}$ amounts more than $80.00 \mathrm{wt} \%$ were extruded favorably, as presented in Figure 2a. This is because the presence of PEG in the ternary blends is conducive to a decrease in viscosity and the improvement in flowability [40]. Further evidence for good structural integrity can be furnished from leached $\mathrm{P}_{80-20}$, as visualized in Figure $2 \mathrm{~b}$. Porous cylinder and disc have the same diameter with the produced extrudate after machining bulk SSE specimens followed by the removal of $\mathrm{NaCl}$ particles and PEG in distilled water. The SSE/porogen leaching approach is flexible enough to engineer porous scaffolds with various shapes to meet different application requirements. 

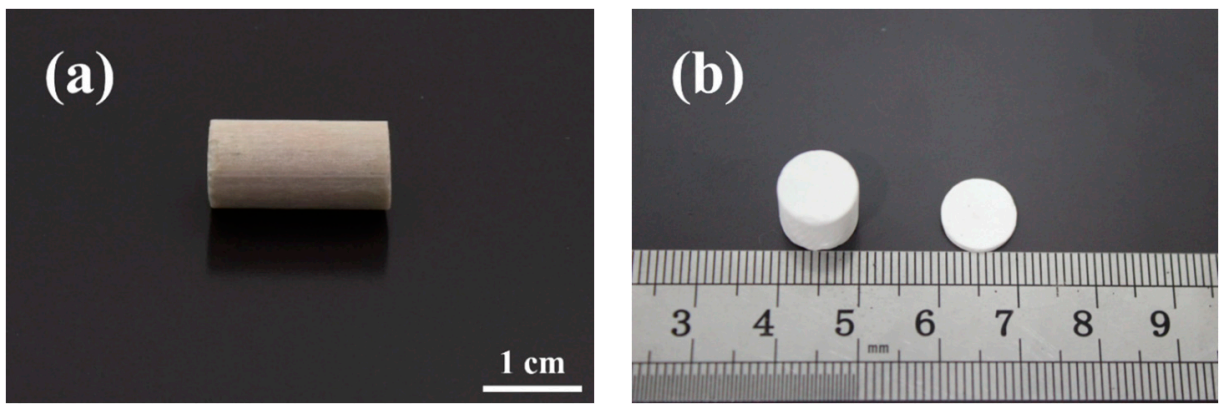

Figure 2. Digital photos of porous PLA scaffolds for $\mathrm{P}_{80-20}$ : (a) before porogen leaching and (b) after machining and porogen leaching.

\subsection{Residual Mass and Connectivity}

TGA was performed to determine the residual mass of $\mathrm{NaCl}$ and the connectivity of porous scaffolds. To exclude the inference of PEG in residual weight, the TGA curve of pure PEG was presented as a control (Figure 3a). In the temperature range of $350-450{ }^{\circ} \mathrm{C}, \mathrm{PEG}$ undergoes primary thermal decomposition and shows $100 \%$ weight loss. This indicates that the ultimate residual mass of porous PLA scaffolds is solely from undissolved $\mathrm{NaCl}$ moiety. The remaining mass percent of all samples is less than $2 \%$, verifying a complete particulate leaching of $\mathrm{NaCl}$ (Figure $3 b$ ). Regarding the sample comprised of $75.00 \mathrm{wt} \% \mathrm{NaCl}\left(\mathrm{P}_{75-5}, \mathrm{P}_{75-10}\right.$ and $\left.\mathrm{P}_{75-20}\right)$, the residual mass decreases with PEG concentration. In addition, the onset decomposition temperature at $5 \%$ weight loss of all the as-prepared PLA scaffolds remains nearly constant at about $280{ }^{\circ} \mathrm{C}$ (Figure 3a). No significant difference in the initial decomposition temperature suggests scarce change of molecular weight in SSE PLA scaffolds.
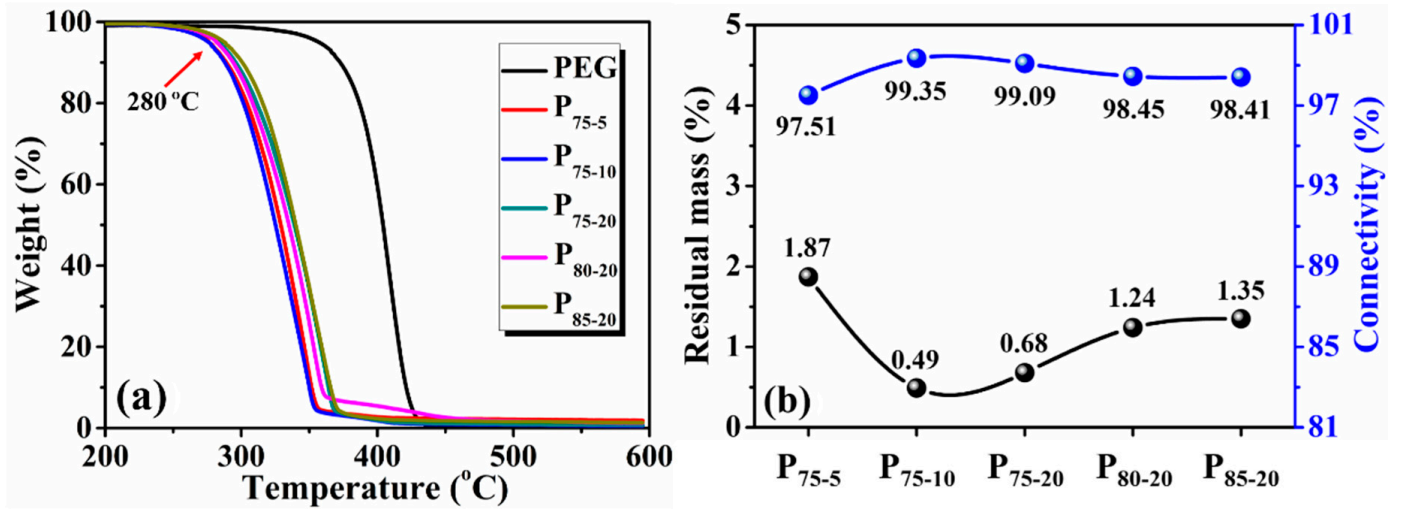

Figure 3. (a) TGA curves of porous PLA scaffolds and PEG control; (b) Residual mass and connectivity as a function of sample composition.

Consistent with a previous report [40], rinsing out water-soluble PEG is in favor of improving pore interconnectivity (Figure 3b). All the porous PLA scaffolds exhibit high connectivity in excess of $97 \%$. This is indicative of the easy formation of an interconnected porous architecture by dint of the SSE/porogen leaching approach [43]. Such an observation is notably superior to prior studies, where $\mathrm{NaCl}$ particles, even at the loading of $80.00 \mathrm{wt} \%$, usually became trapped within the matrix, resulting in unsatisfactory connectivity because of a lack of access to water [24]. The interconnected channels induced by the leaching of PEG is conducive to $\mathrm{NaCl}$ removal, leading to the escalation of connectivity. Therefore, the recommended method provides a pacific yet simple cue for preparing an interconnected structure. 


\subsection{Morphology and Structure}

SEM images of $\mathrm{P}_{80-20}$ are shown as an example to depict the inner structure of the porous PLA scaffolds. A highly interconnected porous architecture in three dimensions appears after the removal of porogen (Figure 4a), in line with the TGA results. The similar structure is observed in other samples except $\mathrm{P}_{85-20}$, in which the collapse of pore structures is observed, likely due to the discontinuous pore connections induced by high $\mathrm{NaCl}$ content and inferior processability (Figure S1). Note that lots of randomly distributed micropores throughout pore walls might be derived from the removal of PEG and diminutive $\mathrm{NaCl}$ particles (Figure 4a). It should be addressed that small channels could not only afford high interconnectivity among pores, as demonstrated in Figure $3 \mathrm{~b}$, but also enable the transport of nutrients and metabolites in scaffolds during cell culturing [44]. Furthermore, leaching hydrosoluble PEG engenders a rough pore wall surface (Figure $4 b$ ), which has a positive effect on promoting cell attachment and proliferation [45]. Similar to Ghosh's report [46], permeable pores located in pore walls accelerate $\mathrm{NaCl}$ removal by the dissolution of PEG. On the other hand, an essential factor of porosity [47] shows a monotonical increase accompanied by the increase in PEG and $\mathrm{NaCl}$ (Figure 4c), reaching from $66.10 \%$ for $\mathrm{P}_{75-5}$ to $80.63 \%$ for $\mathrm{P}_{85-20}$. As expected, the porosity of fabricated PLA scaffolds coincides with the theoretical value (Table 1), further supporting the idea that the full removal of porogen leads to the formation of interconnected pore structure (Figure 3b). Reminiscent of the basic porosity requirement $(60 \%)$ of tissue engineering, the as-prepared porous scaffolds tender enough space to boost cell proliferation and growth [48]. Average pore size estimated from SEM images shows an approximately identical value of $9 \mu \mathrm{m}$, which has little relation to PEG and $\mathrm{NaCl}$ content (Figure $4 \mathrm{~d}$ ). A smaller pore size than the particle size of primitive $\mathrm{NaCl}$ is attributed to the fragmentation of bulky $\mathrm{NaCl}$ caused by intensive shear field and smash action in the processing. Relatively uniform pore distribution and micron-scale pore size ensure enough space for cell infiltration [48].
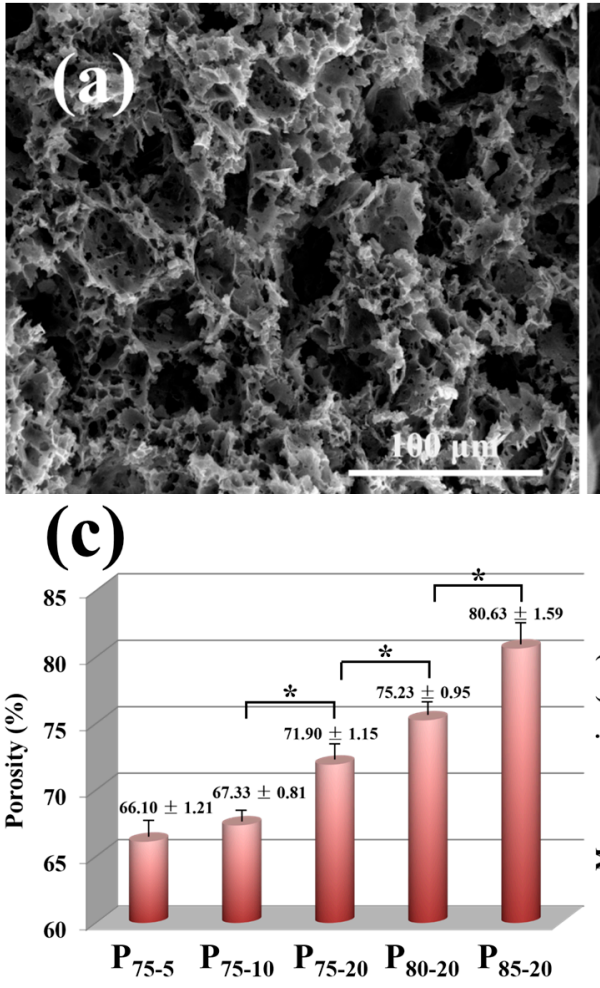
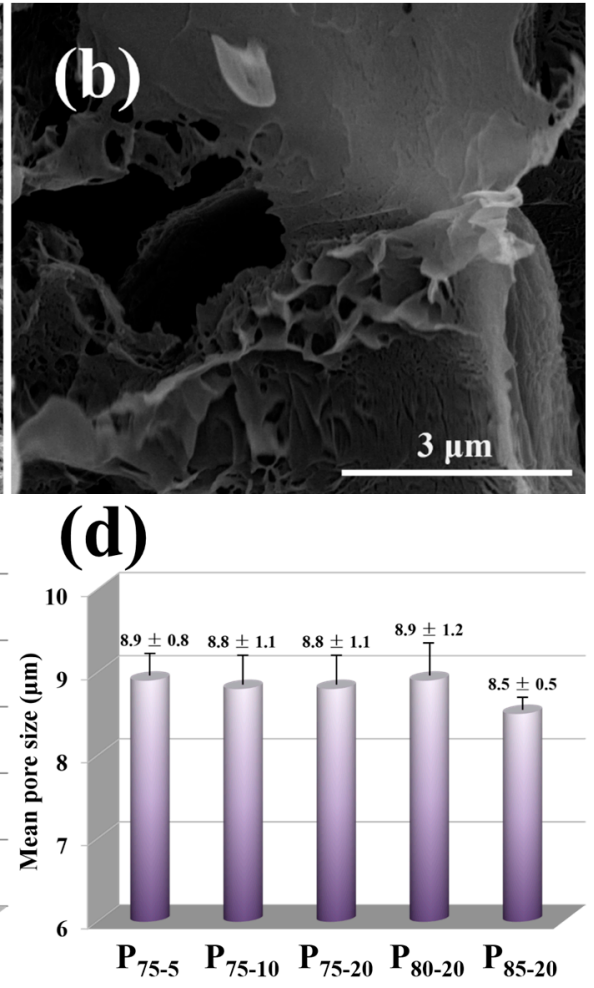

Figure 4. SEM images of (a) fracture surface and (b) pore wall of $P_{80-20}$. (c) Porosity of PLA scaffolds for all sample compositions. (d) Mean pore size of scaffolds acquired from SEM images. * indicates $p<0.05$. 


\subsection{Thermal Behavior}

Since $X_{c}$ of scaffolds strongly influences cell attachment [49], thermal properties of porous PLA scaffolds were further evaluated. As given in Figure $5, X_{\mathrm{c}}$ and melting point $\left(T_{\mathrm{m}}\right)$ are detected from the first heating curves of the PLA scaffolds with varied compositions. Note that all porous PLA scaffolds with the exception of $\mathrm{P}_{85-20}$ display relatively high $X_{\mathrm{c}}$. Upon the introduction of PEG, the increased mobility of PLA chains contributes to the formation of the regular structure [40]. Such well-arranged crystalline structure is envisioned to enhance resistance on compressive deformation. An account of decreased $X_{\mathrm{c}}$ in $\mathrm{P}_{85-20}$ is that high $\mathrm{NaCl}$ content impedes PLA chain mobility and thereby prohibits crystallization. Besides, only a single $T_{\mathrm{m}}$ from $\mathrm{P}_{75-5}$ to $\mathrm{P}_{80-20}$ reflects a homogenous structure of PLA crystals. In contrast, multiple $T_{\mathrm{m}} \mathrm{s}$ emerge in the 1st heating curve of $\mathrm{P}_{85-20}$. Crystal transformation from $\alpha$-form to $\beta$-form disclosed in our previous work may be the reasonable interpretation [50].

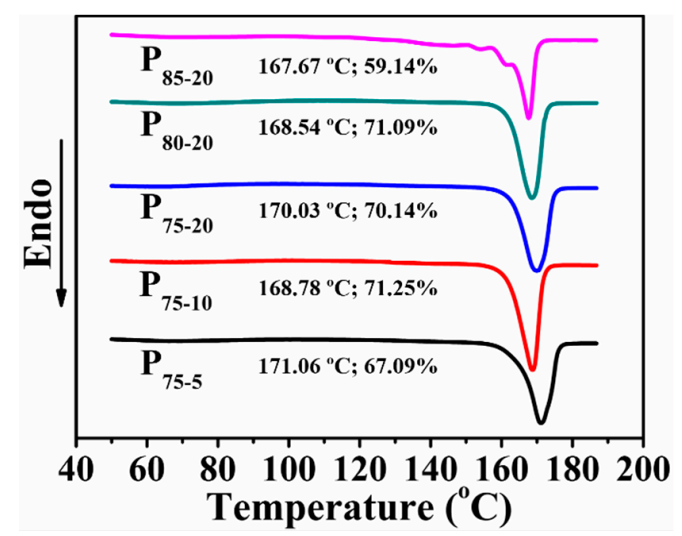

Figure 5. DSC melting thermograms of scaffolds for different compositions.

\subsection{Compressive Properties}

The matched mechanical properties of porous scaffolds are crucial for loading in early transplants and promoting bone reparation [44]. Based on the current perspective, ideal scaffolds require suitable mechanical properties for sustentation so as to match the native tissue. However, it is rarely realized in the porous scaffolds. As seen in Figure 6, the compressive modulus first increases with PEG and then decreases from $\mathrm{P}_{75-10}$ to $\mathrm{P}_{85-20}$, reaching up to 207.4 MPa. Such a high value in the compressive modulus is closely related to the structural transformation induced by the SSE. By driving $\mathrm{PLA} / \mathrm{PEG} / \mathrm{NaCl}$ blends to convergent dies, a more compact and robust polymeric framework is formed. The compressive modulus of porous scaffolds also relies on the structural parameters, such as porosity, pore size, and autologous structure. Since $\mathrm{P}_{75-5}$ and $\mathrm{P}_{75-10}$ have similar porosity and mean pore size (Figure $4 \mathrm{c}, \mathrm{d}$ ), the obvious improvement in compressive modulus could probably be ascribed to the stable internal structure [36]. The increase in PEG content from 1.25 to $2.50 \mathrm{wt} \%$ makes the PLA chain easier to migrate, generating a neater structure, as corroborated by $X_{\mathrm{c}}$ (Figure 5). As a result, $\mathrm{P}_{75-10}$ is capable of withstanding outside force more effectively. Upgrading porosity to porous PLA scaffolds with identical mean pore size and structural regularity can lead to a more open pore structure (Figures 4c,d and 5) and hence impair the compressive modulus from $207.4 \mathrm{MPa}$ in $\mathrm{P}_{75-10}$ to $85.7 \mathrm{MPa}$ in $\mathrm{P}_{80-20}$. In comparison with the PLA scaffolds with analogous porosity once reported (8.4-35.0 MPa) [51,52], the value of compressive modulus in the present work exhibits an over twofold increase, even reaching an unprecedented level [53]. More importantly, the compressive moduli of all sample compositions except $\mathrm{P}_{85-20}$ situates themselves in a middle and even upper level of the normal modulus (50-250 MPa) of human trabecular bone [54]. These results suggest that porous scaffolds gained via the SSE/porogen leaching method are suitable for bone repair. Taking the comprehensive properties of porous PLA scaffolds into account, $\mathrm{P}_{80-20}$ is regarded as the most appropriate candidate to further evaluate its biocompatibility. 


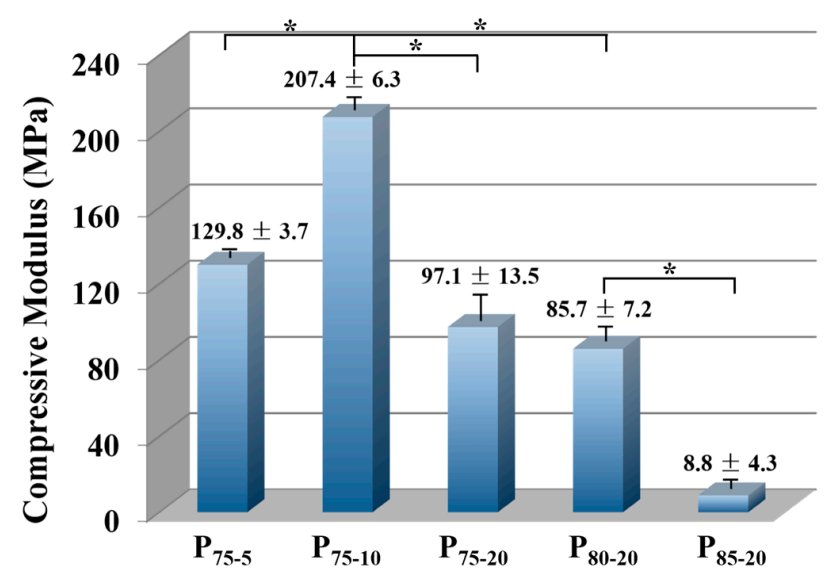

Figure 6. Compressive modulus of scaffolds for different compositions. ${ }^{*}$ indicates $p<0.05$.

\subsection{Surface Wettability}

Since surface wettability of scaffolds intensively affects cell attachment, hydrophilicity of the PLA scaffolds was accessed by measuring the water contact angle (WCA). An average WCA of $112.5^{\circ}$ for $\mathrm{P}_{80-20}$ is observed in Figure 7a, which is due to the hydrophobicity of PLA. As described by Lin et al., a hydrophobic surface precludes cell adhesion in cell culture [55]. Expecting a promotion effect on cell attachment and growth, alkaline modification was introduced to improve wettability [14]. As shown in Figure $7 \mathrm{~b}$, the rapid water infiltration process $(1.716 \mathrm{~s})$ indicates that hydrophilicity of $\mathrm{P}_{80-20}$ is improved by hydrophilic modification overtly.

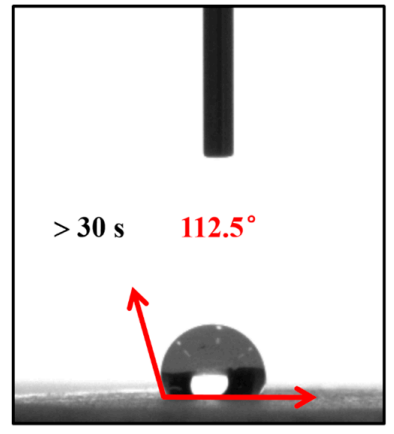

(a)

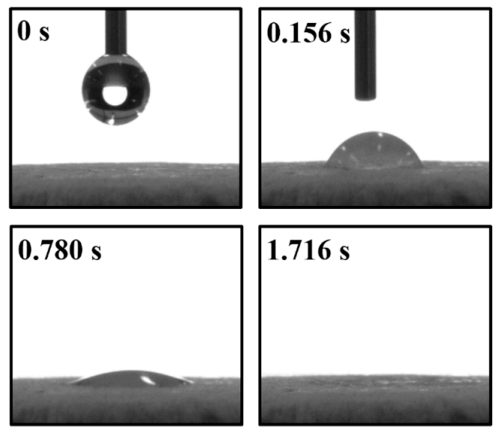

(b)

Figure 7. Water contact angle (WCA) of scaffolds for $\mathrm{P}_{80-20}(\mathbf{a})$ before and (b) after alkaline modification.

\subsection{Cytotoxicity Test and Cell Adhesion}

Rudimentary cytotoxicity test by the extract solution method was adopted to evaluate the cytotoxicity of scaffolds. According to ISO10993-5 (2009), both $\mathrm{P}_{80-20}$ and alkalinity-modified $\mathrm{P}_{80-20}$ show the cell viability to be more than $70 \%$ (Figure $8 \mathrm{a}$ ), manifesting that the porous scaffolds are nontoxic and biocompatible. Qualitative analysis of the BMSC attachment on PLA scaffolds is reflected in fluorescence micrographs (Figure 8c,d). Adequate adhesion throughout the porous construction indicates a good interaction between cells and scaffolds. Meanwhile, the higher cell density and greater amount of spread cells observed in alkalinity-modified $\mathrm{P}_{80-20}$, rather than $\mathrm{P}_{80-20}$, suggest the virtue of modified scaffolds for cell adhesion. Besides, quantitative results of cell adhesion further confirm that more living cells spread on alkalinity-modified $\mathrm{P}_{80-20}$ than the unmodified one (Figure $8 \mathrm{~b}$ ). These results reveal that alkaline modification heightens the applied value of PLA scaffolds in bone tissue engineering. 

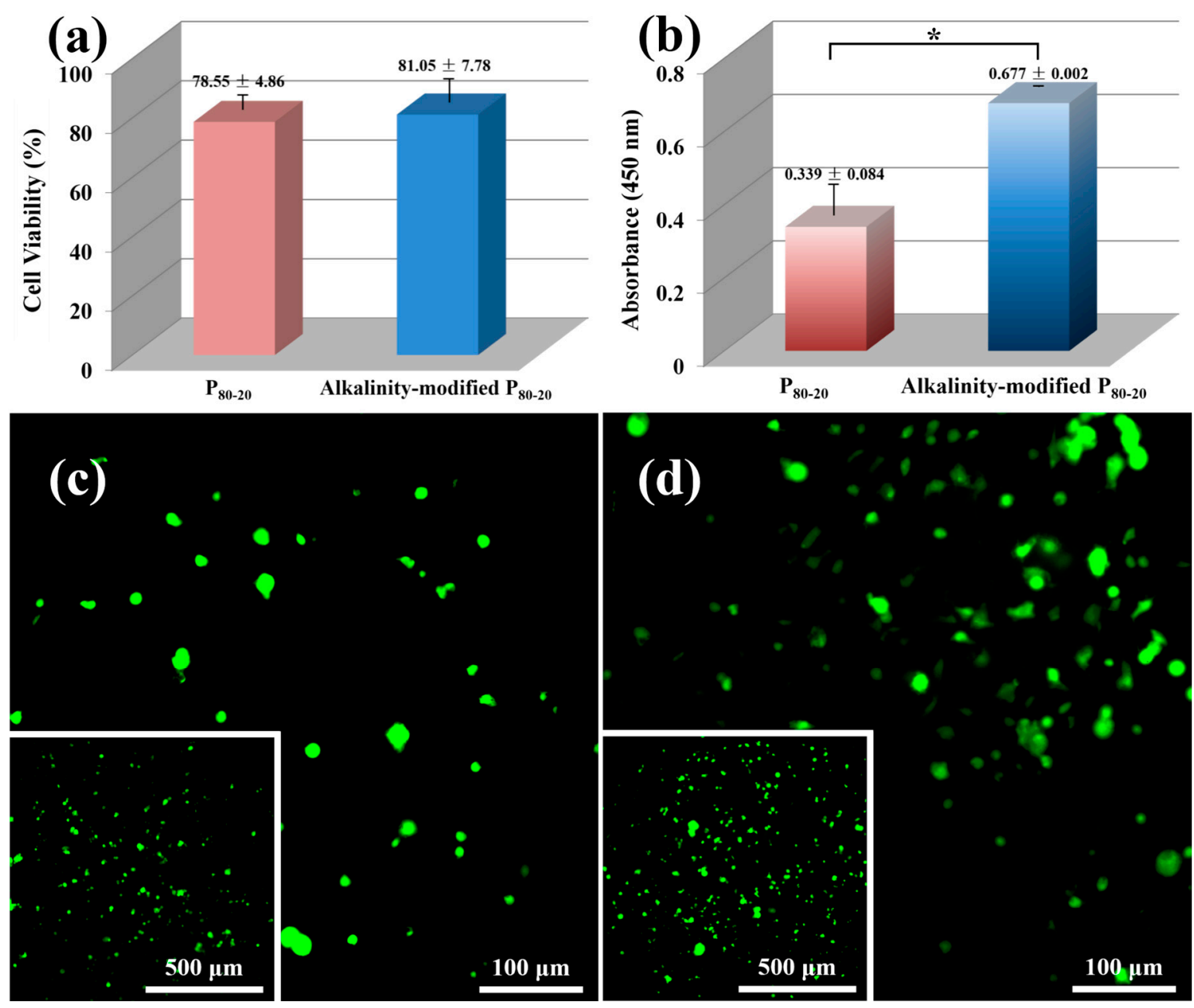

Figure 8. (a) Cytotoxicity of the scaffolds by extract solution analysis. (b) Cell adhesion of the scaffolds cultured for 1 day. Fluorescence image of bone marrow stromal cells (BMSCs) after adhesion on (c) $\mathrm{P}_{80-20}$ and (d) alkalinity-modified $\mathrm{P}_{80-20}$ (live cells are stained in green). The insets of (c) and (d) present low-magnification image of cell morphology. * indicates $p<0.05$.

\section{Conclusions}

Interconnected porous PLA scaffolds were successfully developed via a SSE/water-soluble porogen leaching approach. The presence of PEG not only generated desirable processability of PLA/ $\mathrm{NaCl}$, but also facilitated the occurrence of an interconnected pore. In this scenario, removal of porogen consisted of $\mathrm{NaCl}(>75.00 \mathrm{wt} \%)$ and PEG $(>1.25 \mathrm{wt} \%)$ permitted the construction of a three-dimensional porous architecture with high connectivity, covering a value of more than $97 \%$ and enhanced porosity outperforming $60 \%$, assuring enough space to promote cell proliferation and growth. A significant merit in innumerable micropores and coarse surface topography throughout pore walls was favorable to the flow transport of nutrients and metabolic waste, and cell adhesion. Positively, compressive modulus varying from 85.7 to $207.4 \mathrm{MPa}$ fell in the range of normal modulus of human trabecular bone (50-250 MPa). In vitro cell experiments showed that biocompatible PLA scaffolds promoted cell attachment after alkaline modification. As a whole, porous PLA scaffolds prepared by the SSE/porogen leaching approach integrated desired pore parameters with interconnected structures, good physical performances, as well as biological properties. Thus, our findings display that the SSE/porogen leaching could be fruitfully applied to high-performance porous scaffolds for the use of bone repair. 
Supplementary Materials: Supplementary Materials can be found at www.mdpi.com/2073-4360/8/6/213/s1.

Acknowledgments: The authors gratefully acknowledge the financial support from the Program of National Natural Science of China (51573116, 51533004, 51120135002, and 51421061) and the Sichuan Youth Science and Technology Innovation Research Team (2014TD0002).

Author Contributions: Hua-Mo Yin carried out the experiments and wrote the manuscript. Jing Qian and Jin Zhang were involved in data analysis. Zai-Fu Lin performed the cell experiment. Jian-Shu Li directed the cell experiment. Jia-Zhuang $\mathrm{Xu}$ and Zhong-Ming Li supervised the entire research project. All authors discussed the results and revised the manuscript.

Conflicts of Interest: The authors declare no conflict of interest.

\section{References}

1. Lee, J.; Cuddihy, M.J.; Kotov, N.A. Three-dimensional cell culture matrices: State of the art. Tissue Eng. Part B Rev. 2008, 14, 61-86. [CrossRef] [PubMed]

2. Holzwarth, J.M.; Ma, P.X. Biomimetic nanofibrous scaffolds for bone tissue engineering. Biomaterials 2011, 32, 9622-9629. [CrossRef] [PubMed]

3. Guarino, V.; Causa, F.; Taddei, P.; Di Foggia, M.; Ciapetti, G.; Martini, D.; Fagnano, C.; Baldini, N.; Ambrosio, L. Polylactic acid fibre-reinforced polycaprolactone scaffolds for bone tissue engineering. Biomaterials 2008, 29, 3662-3670. [CrossRef] [PubMed]

4. Wei, G.; Ma, P.X. Partially nanofibrous architecture of 3D tissue engineering scaffolds. Biomaterials 2009, 30, 6426-6434. [CrossRef] [PubMed]

5. Ronca, A.; Ambrosio, L.; Grijpma, D.W. Preparation of designed poly(D,L-lactide)/nanosized hydroxyapatite composite structures by stereolithography. Acta Biomater. 2013, 9, 5989-5996. [CrossRef] [PubMed]

6. Zhu, M.F.; Wang, K.; Mei, J.J.; Li, C.; Zhang, J.M.; Zheng, W.T.; An, D.; Xiao, N.N.; Zhao, Q.; Kong, D.L.; et al. Fabrication of highly interconnected porous silk fibroin scaffolds for potential use as vascular grafts. Acta Biomater. 2014, 10, 2014-2023. [CrossRef] [PubMed]

7. Kim, B.S.; Mooney, D.J. Engineering smooth muscle tissue with a predefined structure. J. Biomed. Mater. Res. 1998, 41, 322-332. [CrossRef]

8. Thomson, R.C.; Wake, M.C.; Yaszemski, M.J.; Mikos, A.G. Biodegradable polymer scaffolds to regenerate organs. Adv. Polym. Sci. 1995, 122, 245-274.

9. Ma, P.X.; Choi, J.W. Biodegradable polymer scaffolds with well-defined interconnected spherical pore network. Tissue Eng. 2001, 7, 23-33. [CrossRef] [PubMed]

10. Hou, Q.P.; Grijpma, D.W.; Feijen, J. Porous polymeric structures for tissue engineering prepared by a coagulation, compression moulding and salt leaching technique. Biomaterials 2003, 24, 1937-1947. [CrossRef]

11. Jung, Y.; Kim, S.S.; Kim, Y.H.; Kim, S.H.; Kim, B.S.; Kim, S.; Choi, C.Y.; Kim, S.H. A poly(lactic acid)/calcium metaphosphate composite for bone tissue engineering. Biomaterials 2005, 26, 6314-6322. [CrossRef] [PubMed]

12. Ghosh, S.; Vianac, J.C.; Reis, R.L.; Mano, J.F. Development of porous lamellar poly(L-lactic acid) scaffolds by conventional injection molding process. Acta Biomater. 2008, 4, 887-896. [CrossRef] [PubMed]

13. Virgilio, N.; Sarazin, P.; Favis, B.D. Towards ultraporous poly(L-lactide) scaffolds from quaternary immiscible polymer blends. Biomaterials 2010, 31, 5719-5728. [CrossRef] [PubMed]

14. Zhang, J.; Yin, H.M.; Hsiao, B.S.; Zhong, G.J.; Li, Z.M. Biodegradable poly(lactic acid)/hydroxyl apatite 3D porous scaffolds using high-pressure molding and salt leaching. J. Mater. Sci. 2014, 49, 1648-1658. [CrossRef]

15. Whang, K.; Thomas, C.H.; Healy, K.E.; Nuber, G. A novel method to fabricate bioabsorbable scaffolds. Polymer 1995, 36, 837-842. [CrossRef]

16. Zhou, C.C.; Ma, L.; Li, W.; Yao, D.G. Fabrication of tissue engineering scaffolds through solid-state foaming of immiscible polymer blends. Biofabrication 2011, 3, 045003. [CrossRef] [PubMed]

17. Vissers, C.A.B.; Harvestine, J.N.; Leach, J.K. Pore size regulates mesenchymal stem cell response to Bioglass-loaded composite scaffolds. J. Mater. Chem. B 2015, 3, 8650-8658. [CrossRef]

18. Nam, Y.S.; Park, T.G. Biodegradable polymeric microcellular foams by modified thermally induced phase separation method. Biomaterials 1999, 20, 1783-1790. [CrossRef]

19. Sun, B.; Jiang, X.J.; Zhang, S.; Zhang, J.C.; Li, Y.F.; You, Q.Z.; Long, Y.Z. Electrospun anisotropic architectures and porous structures for tissue engineering. J. Mater. Chem. B 2015, 3, 5389-5410. [CrossRef] 
20. Pham, Q.P.; Sharma, U.; Mikos, A.G. Electrospinning of polymeric nanofibers for tissue engineering applications: A review. Tissue Eng. 2006, 12, 1197-1211. [CrossRef] [PubMed]

21. Colosi, C.; Costantini, M.; Latini, R.; Ciccarelli, S.; Stampella, A.; Barbetta, A.; Massimi, M.; Devirgiliis, L.C.; Dentini, M. Rapid prototyping of chitosan-coated alginate scaffolds through the use of a 3D fiber deposition technique. J. Mater. Chem. B 2014, 2, 6779-6791. [CrossRef]

22. Forman, S.; Kas, J.; Fini, F.; Steinberg, M.; Ruml, T. The effect of different solvents on the ATP/ADP content and growth properties of HeLa cells. J. Biochem. Mol. Toxicol. 1999, 13, 11-15. [CrossRef]

23. Widmer, M.S.; Gupta, P.K.; Lu, L.C.; Meszlenyi, R.K.; Evans, G.R.D.; Brandt, K.; Savel, T.; Gurlek, A.; Patrick, C.W.; Mikos, A.G. Manufacture of porous biodegradable polymer conduits by an extrusion process for guided tissue regeneration. Biomaterials 1998, 19, 1945-1955. [CrossRef]

24. Cui, Z.X.; Nelson, B.; Peng, Y.Y.; Li, K.; Pilla, S.; Li, W.J.; Turng, L.S.; Shen, C.Y. Fabrication and characterization of injection molded poly( $\varepsilon$-caprolactone) and poly( $\varepsilon$-caprolactone)/hydroxyapatite scaffolds for tissue engineering. Mater. Sci. Eng. C 2012, 32, 1674-1681. [CrossRef] [PubMed]

25. Gu, Y.; Huang, W.; Rahaman, M.N.; Day, D.E. Bone regeneration in rat calvarial defects implanted with fibrous scaffolds composed of a mixture of silicate and borate bioactive glasses. Acta Biomater. 2013, 9, 9126-9136. [CrossRef] [PubMed]

26. Farrell, C.J.; Keller, A. Direct ram extrusion of polyethylene; a correlation between chain-folding and tensile modulus. J. Mater. Sci. 1977, 12, 966-974. [CrossRef]

27. Perkins, W.G.; Porter, R.S. Solid-state deformation of polyethylene and nylon and its effects on their structure and morphology. J. Mater. Sci. 1977, 12, 2355-2388. [CrossRef]

28. Coates, P.D.; Gibson, A.G.; Ward, I.M. Analysis of the mechanics of solid-phase extrusion of polymers. J. Mater. Sci. 1980, 15, 359-375. [CrossRef]

29. Zachariades, A.E.; Mead, W.T.; Porter, R.S. Recent developments in ultra-orientation of polyethylene by solid-state extrusion. Chem. Rev. 1980, 80, 351-364. [CrossRef]

30. Lim, J.Y.; Kim, S.H.; Lim, S.; Kim, Y.H. Improvement of flexural strengths of poly(L-lactic acid) by solid-state extrusion. Macromol. Chem. Phys. 2001, 202, 2447-2453. [CrossRef]

31. Ferguson, S.; Wahl, D.; Gogolewski, S. Enhancement of the mechanical properties of polylactides by solid-state extrusion. II. Poly(L-lactide), poly(L/D-lactide), and poly(L/DL-lactide). J. Biomed. Mater. Res. 1996, 30, 543-551. [CrossRef]

32. Kakinoki, S.; Yamaoka, T. Thermoresponsive elastin/laminin mimicking artificial protein for modifying PLLA scaffolds in nerve regeneration. J. Mater. Chem. B 2014, 2, 5061-5067. [CrossRef]

33. Rasal, R.M.; Janorkar, A.V.; Hirt, D.E. Poly(lactic acid) modifications. Prog. Polym. Sci. 2010, 35, $338-356$. [CrossRef]

34. Wiebe, J.; Hamm, C.W.; Nef, H.M. Bioresorbable scaffolds in daily clinical routine: A practical review of all-comers results. Curr. Opin. Cardiol. 2015, 30, 650-656. [CrossRef] [PubMed]

35. Rasal, R.M.; Hirt, D.E. Toughness decrease of PLA-PHBHHx blend films upon surface-confined photopolymerization. J. Biomed. Mater. Res. A 2009, 88A, 1079-1086. [CrossRef] [PubMed]

36. Zhang, W.H.; Chen, B.Y.; Zhao, H.B.; Yu, P.; Fu, D.J.; Wen, J.S.; Peng, X.F. Processing and characterization of supercritical $\mathrm{CO}_{2}$ batch foamed poly(lactic acid)/poly(ethylene glycol) scaffold for tissue engineering application. J. Appl. Polym. Sci. 2013, 130, 3066-3073. [CrossRef]

37. Llorens, E.; Del Valle, L.J.; Ferrán, R.; Rodríguez-Galán, A.; Puiggalí, J. Scaffolds with tuneable hydrophilicity from electrospun microfibers of polylactide and poly(ethylene glycol) mixtures: Morphology, drug release behavior, and biocompatibility. J. Polym. Res. 2014, 21, 360-374. [CrossRef]

38. Ozcelik, B.; Blencowe, A.; Palmer, J.; Ladewig, K.; Stevens, G.W.; Abberton, K.M.; Morrison, W.A.; Qiao, G.G. Highly porous and mechanically robust polyester poly(ethylene glycol) sponges as implantable scaffolds. Acta Biomater. 2014, 10, 2769-2780. [CrossRef] [PubMed]

39. Serra, T.; Ortiz-Hernandez, M.; Engel, E.; Planell, J.A.; Navarro, M. Relevance of PEG in PLA-based blends for tissue engineering 3D-printed scaffolds. Mater. Sci. Eng. C 2014, 38, 55-62. [CrossRef] [PubMed]

40. Chen, B.Y.; Wang, Y.S.; Mi, H.Y.; Yu, P.; Kuang, T.R.; Peng, X.F.; Wen, J.S. Effect of poly(ethylene glycol) on the properties and foaming behavior of macroporous poly(lactic acid)/sodium chloride scaffold. J. Appl. Polym. Sci. 2014, 131. [CrossRef]

41. Fischer, E.W.; Sterzel, H.J.; Wegner, G. Investigation of structure of solution grown crystals of lactide copolymers by means of chemical-reactions. Kolloid Z. Z. Polym. 1973, 251, 980-990. [CrossRef] 
42. Wu, L.B.; Jing, D.Y.; Ding, J.D. A “room-temperature" injection molding/particulate leaching approach for fabrication of biodegradable three-dimensional porous scaffolds. Biomaterials 2006, 27, 185-191. [CrossRef] [PubMed]

43. Reignier, J.; Huneault, M.A. Preparation of interconnected poly( $\varepsilon$-caprolactone) porous scaffolds by a combination of polymer and salt particulate leaching. Polymer 2006, 47, 4703-4717. [CrossRef]

44. Wu, S.; Liu, X.; Yeung, K.W.K.; Liu, C.; Yang, X. Biomimetic porous scaffolds for bone tissue engineering. Mater. Sci. Eng. R 2014, 80, 1-36. [CrossRef]

45. Wan, Y.Q.; Wang, Y.; Liu, Z.M.; Qu, X.; Han, B.X.; Bei, J.Z.; Wang, S.G. Adhesion and proliferation of OCT-1 osteoblast-like cells on micro-and nano-scale topography structured poly(L-lactide). Biomaterials 2005, 26, 4453-4459. [CrossRef] [PubMed]

46. Ghosh, S.; Viana, J.C.; Reis, R.L.; Mano, J.F. The double porogen approach as a new technique for the fabrication of interconnected poly(L-lactic acid) and starch based biodegradable scaffolds. J. Mater. Sci. Mater. Med. 2007, 18, 185-193. [CrossRef] [PubMed]

47. Liu, X.H.; Ma, P.X. Polymeric scaffolds for bone tissue engineering. Ann. Biomed. Eng. 2004, 32, 477-486. [CrossRef] [PubMed]

48. Zhang, J.; Yan, D.X.; Lei, J.; Xu, J.Z.; Hsiao, B.S.; Li, Z.M. Ultraporous poly(lactic acid) scaffolds with improved mechanical performance using high-pressure molding and salt leaching. J. Appl. Polym. Sci. 2013, 130, 3509-3520. [CrossRef]

49. Badrossamay, M.R.; Balachandran, K.; Capulli, A.K.; Golecki, H.M.; Agarwal, A.; Goss, J.A.; Kim, H.; Shin, K.; Parker, K.K. Engineering hybrid polymer-protein super-aligned nanofibers via rotary jet spinning. Biomaterials 2014, 35, 3188-3197. [CrossRef] [PubMed]

50. Yin, H.M.; Xu, H.; Zhang, J.; Chen, J.B.; Lei, J.; Xu, J.Z.; Li, Z.M. Effects of extrusion draw ratio on the morphology, structure and mechanical properties of poly(L-lactic acid) fabricated using solid state ram extrusion. RSC Adv. 2015, 5, 69016-69023. [CrossRef]

51. Park, J.E.; Todo, M. Characterization of compressive deformation behavior and biocompatibility of bioabsorbable layered PLLA scaffolds. IFMBE Proc. 2010, 31, 1230-1233.

52. Acosta Santamaría, V.; Deplaine, H.; Mariggió, D.; Villanueva-Molines, A.R.; García-Aznar, J.M.; Gómez Ribelles, J.L.; Doblaré, M.; Gallego Ferrer, G.; Ochoa, I. Influence of the macro and micro-porous structure on the mechanical behavior of poly(L-lactic acid) scaffolds. J. Non-Cryst. Solids 2012, 358, 3141-3149. [CrossRef]

53. Ezzati, P.; Ghasemi, I.; Karrabi, M.; Azizi, H.; Fortelny, I. Preparation of porous PLLA/PCL blend by a combination of $\mathrm{PEO}$ phase and $\mathrm{NaCl}$ particulate leaching in PLLA/PCL/PEO/NaCl blend. Iran. Polym. J. 2014, 23, 757-766. [CrossRef]

54. Lin, A.S.P.; Barrows, T.H.; Cartmell, S.H.; Guldberg, R.E. Microarchitectural and mechanical characterization of oriented porous polymer scaffolds. Biomaterials 2003, 24, 481-489. [CrossRef]

55. Oh, S.H.; Kang, S.G.; Kim, E.S.; Cho, S.H.; Lee, J.H. Fabrication and characterization of hydrophilic poly(lactic-co-glycolic acid)/poly(vinyl alcohol) blend cell scaffolds by melt-molding particulate-leaching method. Biomaterials 2003, 24, 4011-4021. [CrossRef]

(C) 2016 by the authors; licensee MDPI, Basel, Switzerland. This article is an open access article distributed under the terms and conditions of the Creative Commons Attribution (CC-BY) license (http://creativecommons.org/licenses/by/4.0/). 